\title{
Lateral flow assays
}

\author{
Katarzyna M. Koczula and Andrea Gallotta
}

Xeptagen SpA, VEGA Science Park, Via delle Industrie 9, Venice, Italy

Correspondence: Andrea Gallotta (gallotta@xeptagen.com)

Lateral flow assays (LFAs) are the technology behind low-cost, simple, rapid and portable detection devices popular in biomedicine, agriculture, food and environmental sciences. This review presents an overview of the principle of the method and the critical components of the assay, focusing on lateral flow immunoassays. This type of assay has recently attracted considerable interest because of its potential to provide instantaneous diagnosis directly to patients. The range and interpretation of results and parameters used for evaluation of the assay will also be discussed. The main advantages and disadvantages of LFAs will be summarized and relevant future improvements to testing devices and strategies will be proposed. Finally, the major recent advances and future diagnostic applications in the LFA field will be explored.

\section{Introduction}

The lateral flow assay (LFA) is a paper-based platform for the detection and quantification of analytes in complex mixtures, where the sample is placed on a test device and the results are displayed within 5-30 min. Low development costs and ease of production of LFAs have resulted in the expansion of its applications to multiple fields in which rapid tests are required. LFA-based tests are widely used in hospitals, physician's offices and clinical laboratories for the qualitative and quantitative detection of specific antigens [1] and antibodies [2], as well as products of gene amplification [3,4]. A variety of biological samples can be tested using LFAs, including urine [5], saliva [6], sweat [7,8], serum [9], plasma [10], whole blood $[10,11]$ and other fluids. Further industries in which LFA-based tests are employed include veterinary medicine [12], quality control [13], product safety in food production [14], and environmental health and safety [15]. In these areas of utilization, rapid tests are used to screen for animal diseases [16], pathogens [17,18], chemicals [19], toxins [20] and water pollutants [21,22], among others.

In recent years there has been an increasing demand for point-of-care multiple diagnostic assays with multiple test lines allowing the rapid and simultaneous detection of multiple analytes present in samples. Such assays (potentially a single LFA) should be easy to perform without the use of laboratory investigation, or individuals trained in chemical analysis. LFAs are very good candidates as they are cheap to produce, easy to use and, importantly, widely accepted by users and regulatory authorities. As the pathway for the development and introduction of novel technologies to the clinical diagnostics market requires hundreds of millions of dollars and decades of work, the improvement and further development of already established LFA technologies is a favourable alternative. This process has the potential to produce devices that may become powerful tools for new challenging applications such as early cancer detection. Moreover, because of the long shelf life and the fact that refrigeration is not required for their storage, LFA are very well adapted for use in developing countries, small ambulatory care settings, remote regions and battlefields.

Depending on the elements of recognition used, LFAs can be categorized into different types (Figure 1). This review focuses on 'lateral flow immunoassays' (LFIAs), in which antibodies are exclusively used as recognition elements. Nucleic acid LFA are used for the detection of amplicons which can be formed during the polymerase chain reaction (PCR) [23]. 


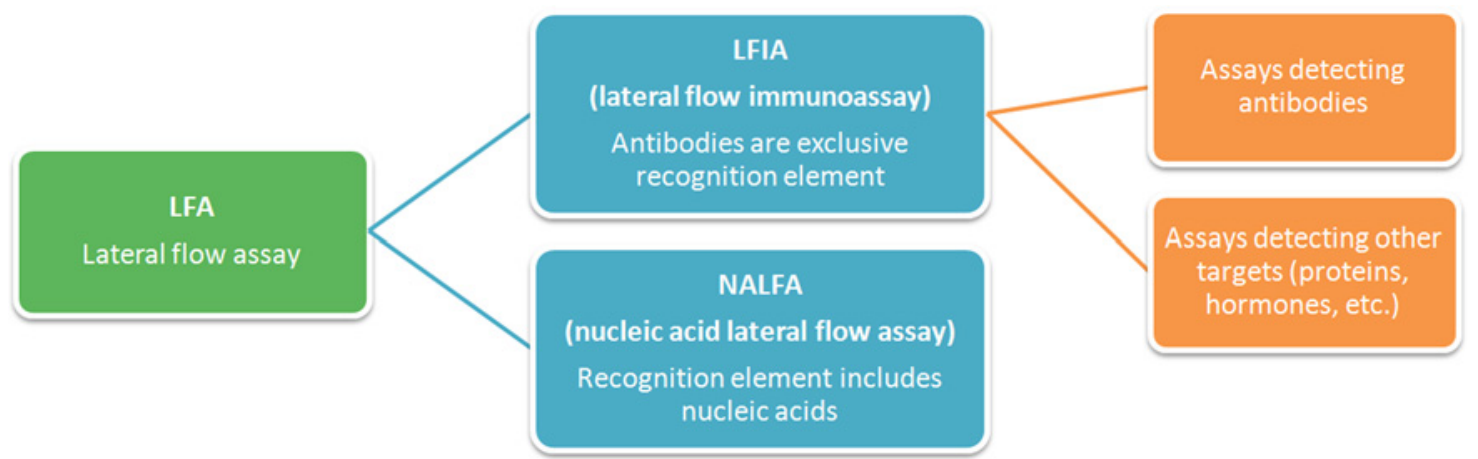

Figure 1. Classification of lateral flow assays

Based on the recognition elements involved in the assay, we can distinguish the lateral flow immunoassay (LFIA) and the nucleic acid lateral flow assay (NALFA).

\section{Principle of the lateral flow immunoassay}

The principle behind the LFA is simple: a liquid sample (or its extract) containing the analyte of interest moves without the assistance of external forces (capillary action) through various zones of polymeric strips, on which molecules that can interact with the analyte are attached. A typical lateral flow test strip (presented in Figure 2) consists of overlapping membranes that are mounted on a backing card for better stability and handling. As shown in Figure 3, the sample is applied at one end of the strip, on the adsorbent sample pad, which is impregnated with buffer salts and surfactants that make the sample suitable for interaction with the detection system. The sample pad ensures that the analyte present in the sample will be capable of binding to the capture reagents of conjugates and on the membrane. The treated sample migrates through the conjugate release pad, which contains antibodies that are specific to the target analyte and are conjugated to coloured or fluorescent particles - most commonly colloidal gold and latex microspheres. The sample, together with the conjugated antibody bound to the target analyte, migrates along the strip into the detection zone. This is a porous membrane (usually composed of nitrocellulose) with specific biological components (mostly antibodies or antigens) immobilized in lines. Their role is to react with the analyte bound to the conjugated antibody. Recognition of the sample analyte results in an appropriate response on the test line, while a response on the control line indicates the proper liquid flow through the strip. The read-out, represented by the lines appearing with different intensities, can be assessed by eye or using a dedicated reader. In order to test multiple analytes simultaneously under the same conditions, additional test lines of antibodies specific to different analytes can be immobilized in an array format $[24,25]$. On the other hand, multiple test lines loaded with the same antibody can be used for semi-quantitative assays. The principle of this 'ladder bars' assay is based on the stepwise capture of colorimetric conjugate-antigen complexes by the immobilized antibody on each successive line, where the number of lines appearing on the strip is directly proportional to the concentration of the analyte [26-28]. The liquid flows across the device because of the capillary force of the strip material and, to maintain this movement, an absorbent pad is attached at the end of the strip. The role of the absorbent pad is to wick the excess reagents and prevent backflow of the liquid.

Two formats of the LFIA can be distinguished: direct and competitive. A direct test is used for larger analytes such as the p24 antigen used in the human immunodeficiency virus (HIV) test ([30] and http://www.orasure.com/products-infectious/products-infectious-oraquick.asp), as well as analytes with multiple antigenic sites such as human chorionic gonadotropin (hCG) used in pregnancy tests [31]. The hCG test is an example of a sandwich-based assay, where the target is immobilized between two complementary antibodies. In the direct test, the presence of the test line indicates a positive result and the control line usually contains species-specific anti-immunoglobulin antibodies, specific for the antibody in the particular conjugate. In the case of small molecules with single antigenic determinants, which cannot bind to two antibodies simultaneously, competitive tests are used. In this type of test, the analyte blocks the binding sites on the antibodies on the test line, preventing their interactions 


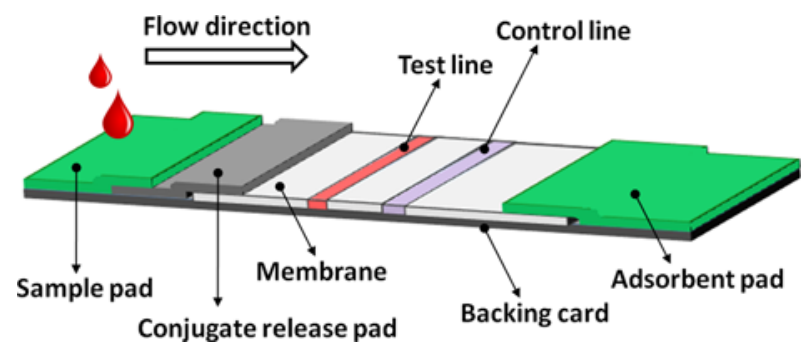

Figure 2. Typical configuration of a lateral flow immunoassay test strip

LFA is usually composed of the following elements: sample pad, conjugate release pad, membrane with immobilized antibodies and adsorbent pad. The components of the strip are usually fixed to an inert backing material.

A
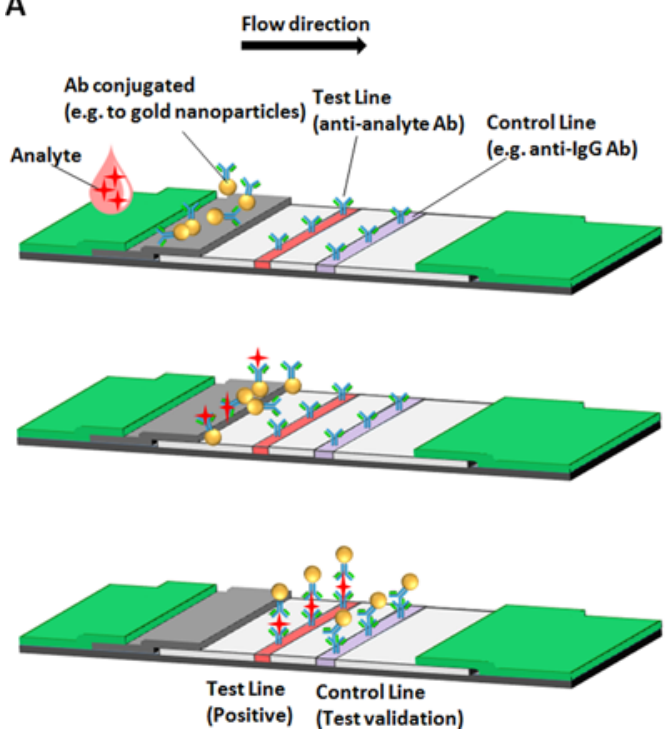

B

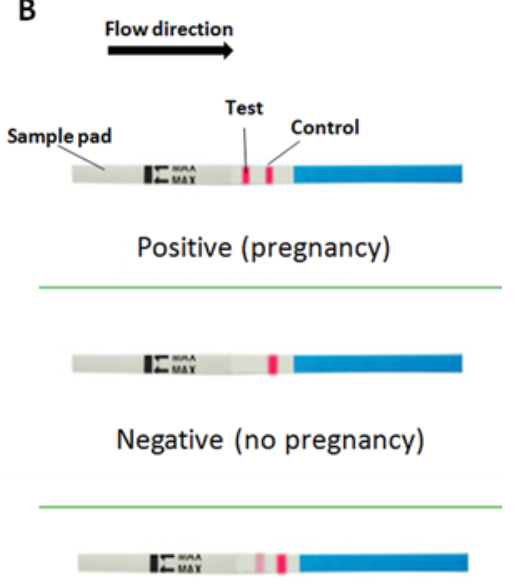

Weak positive

(test should be repeated)

Figure 3. Operation of a lateral flow immunoassay

(A) Schematic representation of the assay's mechanism. Top: the sample is deposited on the sample pad and migrates towards the conjugate. Middle: the conjugated antibodies bind the target analyte and (bottom) migrate to the test line, where the bound target analyte is captured. (B) The most commonly used LFA is the pregnancy test (One Step hCG Urine Test), which uses hCG strips. Possible results and interpretation of the test are shown. In the case of a weak positive result, it is recommended to repeat the test 1 week later. Ab, antibody.

with the coloured conjugate. Therefore, a positive result is indicated by the lack of signal in the test line, while the control line should be visible independently of the test result.

\section{Components of the assay}

The most common difficulties in the manufacture of LFA devices are caused by the hidden complexity of the device. As the test is composed of many elements, problems can be caused by material incompatibility, flaws in the connection of the overlapping elements or imperfect material characteristics. During the development of LFIAs, most attention has been focused on finding the most suitable detection method or choosing the best antigen or antibody. Nonetheless, it is very important to pay attention to all elements of the test, including the basic components such as the backing card, adhesive strip and cover tape, in order to produce a consistent and high-quality product. 


\section{Antibody}

Although the physical components of the test strip, construction techniques and buffers play the major role in optimizing the test, the heart of these processes are the antibodies, which need to be carefully designed and highly purified. It is very important to ensure a consistent antibody supply with proven affinity and specificity. Use of monoclonal antibodies (mostly derived from mouse hybridomas) is preferable, as it allows the production of specific antibodies in large quantities.

\section{Label}

The most important requirements of the nanoparticle label include:

- colloidal stability in solution under various conditions and temperatures

- $\quad$ susceptibility for detection over a large (and useful) dynamic range

- efficiency and reproducibility of conjugation (without the loss of chemical and biological integrity and activity)

- lack of or very low non-specific binding characteristics (ensuring a high signal-to-noise ratio)

- commercial availability at low cost

- $\quad$ easy and scalable conjugation procedure.

Nowadays colloidal gold is the most widely used label in commercial LFIA. Although it can be prepared in the laboratory at low cost, there are many commercial sources available. It has an intense colour and no development process is needed for visualization. Moreover, it has high stability in both liquid and dried forms. Another popular label is latex, which can be tagged with a variety of detector reagents such as coloured or fluorescent dyes, and magnetic or paramagnetic components. As latex can be produced in multiple colours, it has an application in multiplex assays, which require discrimination between numerous lines. Carbon and fluorescent labels, or enzymatic modification $[32,33]$ of the labels, are also used to improve the sensitivity of the assay. Carbon nanotubes have been shown to exhibit a limit of detection that is 10-fold lower than that of gold [34]. Fluorescent nanoparticles such as quantum dots may result in a high background noise which has been shown to be overcome by polymer encapsulation and surface blocking [35].

\section{Membrane}

The membrane is considered the most critical element in LFA strips and nitrocellulose is by far the most commonly used material. Moreover, there are also 'pillar-based' capillary LFA devices used for deoxyribonucleic acid (DNA) hybridization detection (where micropillar arrays replace the membrane), which have the advantage of more precise control of the capillary flow [36]. Important parameters characterizing a good membrane material are the capillary forces, as well as the ease of binding and immobilizing proteins necessary for subsequent selection, reaction and detection. A range of nitrocellulose pore sizes are available, from 0.05 to $12 \mu \mathrm{m}$. However, as the pores are not equally distributed (because of the manufacturing process), capillary flow time is a more accurate parameter and it should be used when selecting the most effective strip material. The capillary flow time is the time required for the liquid to travel to and completely fill the strip of the membrane.

\section{Sample pad}

The sample pad can have multiple roles, the most important of which is to evenly distribute the sample and to direct it to the conjugate pad. The sample pad is usually impregnated with buffer salts, proteins, surfactants and other liquids to control the flow rate of the sample and to make it suitable for the interaction with the detection system. Moreover, the pores of the sample pad can act as a filter in order to remove redundant materials, e.g. red blood cells (Figure 4).

\section{Conjugate pad}

The main role of the conjugate pad is to hold the detector particles and keep them functionally stable until the test is performed. This is ensured by the composition of the conjugate buffer, containing carbohydrates (such as sucrose), which serve as a preservative and a resolubilization agent. When the conjugate particles are dried in the presence of sugar, the sugar molecules form a layer around them stabilizing their biological structures [37]. When the sample enters the conjugate pad, the sugar molecules rapidly dissolve carrying the particles into the fluid stream. It is crucial that the release is consistent between individual test strips. 
Step 1: Blood Collection

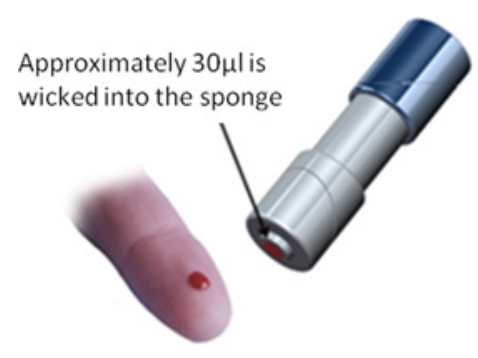

Step 3: Red blood cells separation

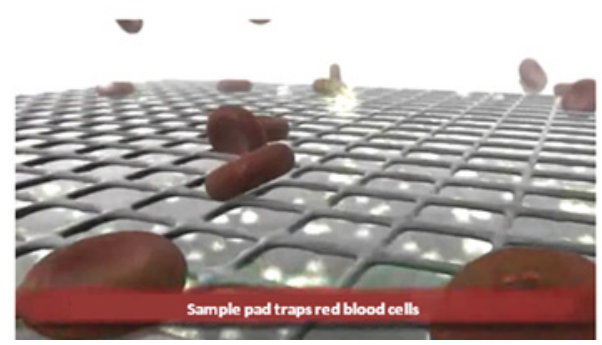

Step 2: The Buffer Module is pressed

onto the sample pad

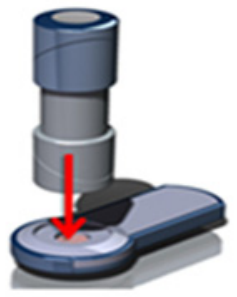

Step 4: After the test run, the result can be quantified using a LFA reader

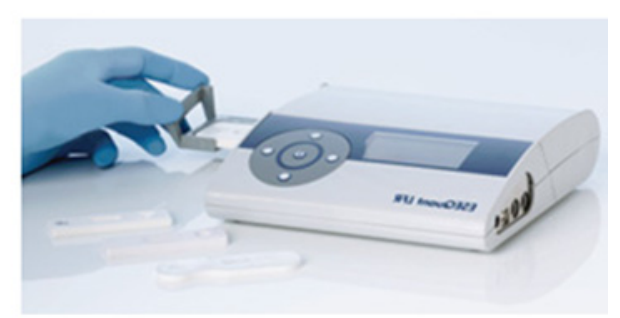

Figure 4. An example of an integrated sample collection device combined with a cassette and strip reader

The device is designed for easy collection of a whole blood sample and running of a quantitative test strip. Red blood cells are mechanically separated on the sample pad. (Pictures adapted from http://www.dcndx.com and https://www.youtube.com/watch?v=FvllozN58gw).

\section{Absorbent pad}

The role of the absorbent pad is to wick the fluid through the membrane and to collect the processed liquid. The absorbent pad allows the use of larger sample volumes, which results in increased test sensitivity. The most popular absorbent pads are made of cellulose filters.

\section{Detection methods}

Since the LFIA is an antibody-based technique, specificity and sensitivity may be affected by other chemicals with similar structures, leading to false positive results. The sensitivity of assays is limited by the $K_{\mathrm{d}}$ (dissociation constant) of the antibody-antigen conjugate and by the colorimetric read-out. In order to overcome these limitations, both readers and novel biochemical techniques have been developed to improve product quality and customer convenience. The selection of a detection system is mainly determined by the label employed in the analysis. Fluorescent dyes or paramagnetic particles cannot be detected directly by the naked eye and require dedicated readers for quantitative analysis (Table 1). Moreover, automated detection methods provide advantages over manual imaging and processing in terms of time consumption, interpretation of results and adjustment of variables.

\section{Advantages and disadvantages of LFAs}

Many LFIAs are designed for use at point-of-care/need, providing cheap, rapid and easy tests desirable in many industries. However, regulatory bodies often require confirmation of results using an independent method. Therefore, LFIA are only suitable for primary screening at point-of-care/need. Because of their long shelf life and the fact that refrigeration is not required for storage, these tests are very well adapted for use in developing countries. As the visual result is usually clear and easily distinguished, no additional specific equipment is needed. A summary of the advantages and disadvantages of LFAs is presented in Figure 5. Research is on-going to address some of the key weaknesses 
Table 1. The most commonly used detection methods employed in lateral flow assays

Examples of applications of these systems can be found in optical readers [45,46], camera readers [47], ladder bars [26], fluorescent readers [48], chemiluminescent readers [49] and electrochemical readers [50]. Examples of labels include: fluorescent [51,52], paramagnetic [47,53], enzyme [54,55] and carbon nanoparticles [34].

\begin{tabular}{|l|l|l|l|}
\hline Labels & Quantitative & Semi-quantitative & Qualitative \\
\hline $\begin{array}{l}\text { Colour labels } \\
\text { e.g. gold nanoparticles, } \\
\text { coloured latex }\end{array}$ & $\begin{array}{l}\text { Optical strip readers or camera } \\
\text { (with imaging software) for } \\
\text { measurement of the intensity } \\
\text { of colours produced at test and } \\
\text { control line }\end{array}$ & $\begin{array}{l}\text { Visual inspection of } \\
\text { ladder bar, where the } \\
\text { number of coloured } \\
\text { lines is an indication } \\
\text { of analyte } \\
\text { concentration }\end{array}$ & $\begin{array}{l}\text { Visual } \\
\text { inspection of } \\
\text { line colours }\end{array}$ \\
\cline { 1 - 2 } $\begin{array}{l}\text { Fluorescent labels } \\
\text { e.g. quantum dots, } \\
\text { ruthenium complexes }\end{array}$ & $\begin{array}{l}\text { Fluorescent strip reader, } \\
\text { recording fluorescence } \\
\text { intensity }\end{array}$ & \\
\cline { 1 - 1 } $\begin{array}{l}\text { Other labels } \\
\text { e.g. paramagnetic labels, } \\
\text { enzyme labels, carbon } \\
\text { nanoparticles }\end{array}$ & $\begin{array}{l}\text { Magnetic strip readers; } \\
\text { Electrochemical detectors; } \\
\text { Chemiluminescence readers }\end{array}$ & & \\
\hline
\end{tabular}

of LFAs, especially with respect to quantitative results. Data can be digitized using scanners or cameras with dedicated software, which will also allow the documentation of results. However, technological improvements will affect the cost of apparatus and the duration of analysis.

\section{New strategies in LFAs}

In recent years, the major advances in LFA development have included novel signal-amplification strategies, applications of new labels, improved quantification systems and simultaneous detection. Some of the new strategies used to enhance the signal from the colloidal gold nanoparticles (GNPs) have adopted silver enhancement technology [38,39] or combinations of GNPs with an enzyme (such as horseradish peroxidase), which results in catalytic amplification of the signal [33]. To improve the detection sensitivity, novel reagents have been identified, including magnetic particles such as nano-gold microspheres, or immune-nanoparticles, which reduce the detection limits to at least $0.1 \mathrm{ng} / \mathrm{ml}$ [40]. Another way to increase assay sensitivity is the implementation of a suitable quantity system such as a thermal contrast, laser or light-emitting diode (LED), which can result in signal amplification up to 1000-fold [41]. Some successful developments of simultaneous detection techniques have been described. These include a combination of colloidal gold nanoparticles and oligonucleotides for the simultaneous detection of antigens and antibodies [42] and the use of two conjugate pads for the simultaneous detection of two proteins [43]. Moreover, combinations of LFAs with computational methods have led to the first example of combinations with electronic logic gates such as 'OR' and 'AND', providing a novel logic-sensing platform [44].

\section{Discussion}

In order to address the criteria demanded by next-generation diagnostic markets, some of the fundamental features of LFAs must be improved. First, assays need to be more reproducible and sensitive, easier to manufacture and operate, and most importantly from a clinical point of view, they should provide relevant results that correlate with other laboratory-based diagnostic systems. Automation of the manufacturing process and sample application, as well as improved read-out and data processing, are required to achieve these aims. Moreover, material science should be applied to bring novel more appropriate custom-designed materials into use, as well as the introduction of new labelling and reading technologies. The use of new labels such as quantum dots and the upconverting phosphors (microscopic ceramic powders that convert infrared light wavelengths into visible coloured light) will improve sensitivity, allowing the use of samples with lower concentrations of the analyte such as sweat or salvia. In 

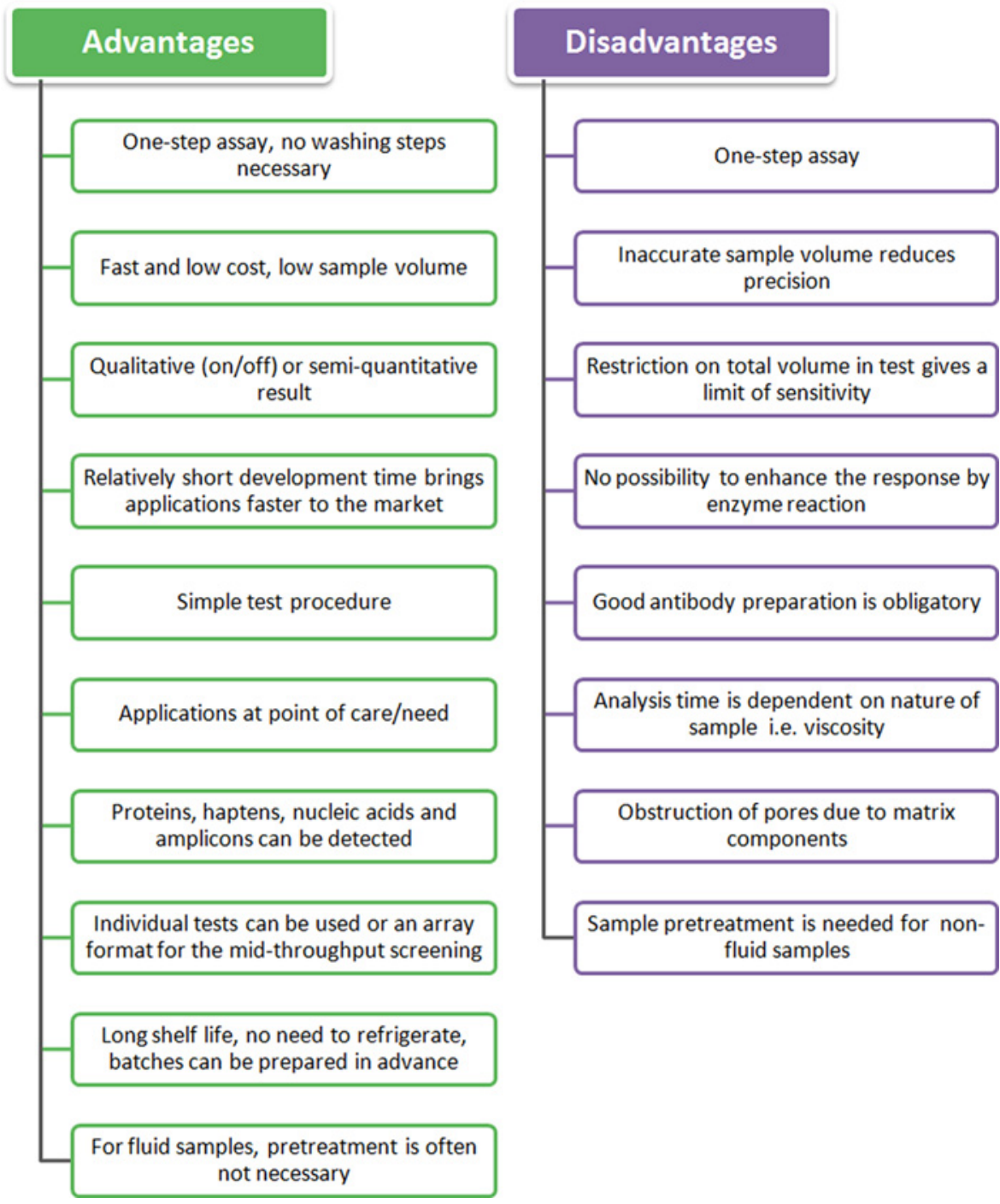

Figure 5. Advantages and disadvantages of the lateral flow assay

Adapted from [49].

the Western world, integration of LFA into a lab-on-a-chip design may bring additional advantages, but will also increase costs. For the non-laboratory-based applications, the LFAs should remain simple and affordable; however, good recognition elements must be available and visual qualitative (on/off) or semi-quantitative results must be sufficient.

\section{Conclusion}

The unique and remarkable properties of LFAs have contributed to the detection of disease biomarkers and infectious agents in medicine, agriculture, food and environmental safety. Although the principle of the method has remained unchanged for decades, there have been continuous improvements of LFA techniques leading to increased sensitivity and reproducibility, and the simultaneous detection of several analytes. Importantly, these assays can now be effectively performed outside the laboratory, providing great advantages for use in developing countries and at the point-of-care, whether in the field or in more traditional clinical settings. 


\section{Summary}

- Lateral flow assays (LFAs) can be used for the detection of proteins, haptens, nucleic acids and amplicons.

- LFAs are well established as a valuable tool in medical, veterinary, food, agricultural and environmental settings and for use in industrial diagnostics.

- The principle of an LFA is based on the movement of a liquid sample though a polymeric strip with attached molecules that interact with the analyte, providing a signal that can be visually detected.

- Although the concept behind the LFA is simple, the device has a complex architecture and many critical elements need to be considered during instrumental design.

- The most critical elements of the assay are the antibodies and the membrane, but attention should be paid to all of the materials used to ensure the compatibility and consistency of the product.

- An LFA is a fast, low cost, portable and easy-to-use assay; however, the results are mostly qualitative (on/off) or semi-quantitative.

- An LFA is usually used for initial screening, which can be confirmed later by a fully quantitative method.

- LFA devices can be evaluated using parameters such as sensitivity, specificity and efficiency.

- Recent advances and future goals for improving LFAs are focused on identifying new signal amplification strategies, nanoparticle labels and quantification systems, as well as improving simultaneous detection.

\section{Abbreviations}

GNP, gold nanoparticle; hCG, human chorionic gonadotropin; LFA, lateral flow assay; LFIA, lateral flow immunoassay.

\section{Funding}

We acknowledge funding from the European Commission Framework Programme 7 through the Marie Curie Initial Training Network PROSENSE [grant number 317420, 2012-2016].

\section{Competing Interests}

The Authors declare that there are no competing interests associated with the manuscript.

\section{References}

1 Boisen, M.L., Oottamasathien, D., Jones, A.B., Millett, M.M., Nelson, D.S., Bornholdt, Z.A. et al. (2015) Development of prototype filovirus recombinant antigen immunoassays. J. Infect. Dis. 212 (Suppl. 2), S359-367 CrossRef PubMed

2 Nielsen, K., Yu, W.L., Kelly, L., Bermudez, R., Renteria, T., Dajer, A. et al. (2008) Development of a lateral flow assay for rapid detection of bovine antibody to Anaplasma marginale. J. Immunoassay Immunochem. 29, 10-18 CrossRef PubMed

3 Rohrman, B.A., Leautaud, V., Molyneux, E. and Richards-Kortum, R.R. (2012) A lateral flow assay for quantitative detection of amplified HIV-1 RNA. PLoS 0ne 7, e45611 CrossRef PubMed

4 Kamphee, H., Chaiprasert, A., Prammananan, T., Wiriyachaiporn, N., Kanchanatavee, A. and Dharakul, T. (2015) Rapid molecular detection of multidrug-resistant tuberculosis by PCR-nucleic acid lateral flow immunoassay. PLos One 10, e0137791 CrossRef PubMed

5 Moreno, M.L., Cebolla, A., Munoz-Suano, A., Carrillo-Carrion, C., Comino, I., Pizarro, A. et al. (2015) Detection of gluten immunogenic peptides in the urine of patients with coeliac disease reveals transgressions in the gluten-free diet and incomplete mucosal healing. Gut, doi:10.1136/gutjnl-2015-310148

6 Carrio, A., Sampedro, C., Sanchez-Lopez, J.L., Pimienta, M. and Campoy, P. (2015) Automated low-cost smartphone-based lateral flow saliva test reader for drugs-of-abuse detection. Sensors 15, 29569-29593 CrossRef PubMed

7 Pacifici, R., Farre, M., Pichini, S., Ortuno, J., Roset, P.N., Zuccaro, P. et al. (2001) Sweat testing of MDMA with the Drugwipe analytical device: a controlled study with two volunteers. J. Anal. Toxicol. 25, 144-146 CrossRef PubMed

8 De Giovanni, N. and Fucci, N. (2013) The current status of sweat testing for drugs of abuse: a review. Curr. Med. Chem. 20, 545-561 PubMed

9 Magambo, K.A., Kalluvya, S.E., Kapoor, S.W., Seni, J., Chofle, A.A., Fitzgerald, D.W. et al. (2014) Utility of urine and serum lateral flow assays to determine the prevalence and predictors of cryptococcal antigenemia in HIV-positive outpatients beginning antiretroviral therapy in Mwanza, Tanzania. J. Int. AIDS Soc. 17, 19040 CrossRef PubMed

10 Schramm, E.C., Staten, N.R., Zhang, Z., Bruce, S.S., Kellner, C., Atkinson, J.P. et al. (2015) A quantitative lateral flow assay to detect complement activation in blood. Anal. Biochem. 477, 78-85 CrossRef PubMed 
11 Ang, S.H., Rambeli, M., Thevarajah, T.M., Alias, Y.B. and Khor, S.M. (2015) Quantitative, single-step dual measurement of hemoglobin A1c and total hemoglobin in human whole blood using a gold sandwich immunochromatographic assay for personalized medicine. Biosens. Bioelectron. 78, 187-193 CrossRef PubMed

12 Nielsen, K., Yu, W.L., Kelly, L., Williams, J., Dajer, A., Gutierrez, E. et al. (2009) Validation and field assessment of a rapid lateral flow assay for detection of bovine antibody to Anaplasma marginale. J. Immunoassay Immunochem. 30, 313-321 CrossRef PubMed

13 van Dam, G.J., de Dood, C.J., Lewis, M., Deelder, A.M., van Lieshout, L., Tanke, H.J. et al. (2013) A robust dry reagent lateral flow assay for diagnosis of active schistosomiasis by detection of Schistosoma circulating anodic antigen. Exp. Parasitol. 135, 274-282 CrossRef PubMed

14 Ching, K.H., He, X., Stanker, L.H., Lin, A.V., McGarvey, J.A. and Hnasko, R. (2015) Detection of shiga toxins by lateral flow assay. Toxins 7 , 1163-1173 CrossRef PubMed

15 Mei, Z., Qu, W., Deng, Y., Chu, H., Cao, J., Xue, F. et al. (2013) One-step signal amplified lateral flow strip biosensor for ultrasensitive and on-site detection of bisphenol $A$ (BPA) in aqueous samples. Biosens. Bioelectron. 49, 457-461 CrossRef PubMed

16 Kim, Y.K., Lim, S.I., Cho, I.S., Cheong, K.M., Lee, E.J., Lee, S.O. et al. (2015) A novel diagnostic approach to detecting porcine epidemic diarrhea virus: the lateral immunochromatography assay. J. Virol. Methods 225, 4-8 CrossRef

17 Shukla, S., Leem, H., Lee, J.S. and Kim, M. (2014) Immunochromatographic strip assay for the rapid and sensitive detection of Salmonella Typhimurium in artificially contaminated tomato samples. Can. J. Microbiol. 60, 399-406 CrossRef PubMed

18 Morales-Narvaez, E., Naghdi, T., Zor, E. and Merkoci, A. (2015) Photoluminescent lateral-flow immunoassay revealed by graphene oxide: highly sensitive paper-based pathogen detection. Anal. Chem. 87, 8573-8577 CrossRef PubMed

19 Ngom, B., Guo, Y., Wang, X. and Bi, D. (2010) Development and application of lateral flow test strip technology for detection of infectious agents and chemical contaminants: a review. Anal. Bioanal. Chem. 397, 1113-1135 CrossRef PubMed

20 Shyu, R.H., Shyu, H.F., Liu, H.W. and Tang, S.S. (2002) Colloidal gold-based immunochromatographic assay for detection of ricin. Toxicon 40 , 255-258 CrossRef PubMed

21 Kuang, H., Xing, C., Hao, C., Liu, L., Wang, L. and Xu, C. (2013) Rapid and highly sensitive detection of lead ions in drinking water based on a strip immunosensor. Sensors 13, 4214-4224 CrossRef PubMed

22 Lopez Marzo, A.M., Pons, J., Blake, D.A. and Merkoci, A. (2013) High sensitive gold-nanoparticle based lateral flow Immunodevice for $\mathrm{Cd}^{2+} \mathrm{detection}^{2}$ in drinking waters. Biosens. Bioelectron. 47, 190-198 CrossRef PubMed

23 Connelly, J.T., Nugen, S.R., Borejsza-Wysocki, W., Durst, R.A., Montagna, R.A. and Baeumner, A.J. (2008) Human pathogenic Cryptosporidium species bioanalytical detection method with single oocyst detection capability. Anal. Bioanal. Chem. 391, 487-495 CrossRef PubMed

24 Xu, Y., Liu, Y., Wu, Y., Xia, X., Liao, Y. and Li, Q. (2014) Fluorescent probe-based lateral flow assay for multiplex nucleic acid detection. Anal. Chem. 86, 5611-5614 CrossRef PubMed

25 Yen, C.W., de Puig, H., Tam, J.0., Gomez-Marquez, J., Bosch, I., Hamad-Schifferli, K. et al. (2015) Multicolored silver nanoparticles for multiplexed disease diagnostics: distinguishing Dengue, yellow fever, and Ebola viruses. Lab Chip 15, 1638-1641 CrossRef PubMed

26 Fung, K.K., Chan, C.P. and Renneberg, R. (2009) Development of enzyme-based bar code-style lateral-flow assay for hydrogen peroxide determination. Anal. Chim. Acta 634, 89-95 CrossRef PubMed

27 Fang, C., Chen, Z., Li, L. and Xia, J. (2011) Barcode lateral flow immunochromatographic strip for prostate acid phosphatase determination. J. Pharm. Biomed. Anal. 56, 1035-1040 CrossRef PubMed

28 Leung, W., Chan, C.P., Rainer, T.H., Ip, M., Cautherley, G.W. and Renneberg, R. (2008) InfectCheck CRP barcode-style lateral flow assay for semi-quantitative detection of C-reactive protein in distinguishing between bacterial and viral infections. J. Immunol. Methods $\mathbf{3 3 6}$, 30-36 CrossRef PubMed

29 Reference deleted

30 Workman, S., Wells, S.K., Pau, C.P., Owen, S.M., Dong, X.F., LaBorde, R. et al. (2009) Rapid detection of HIV-1 p24 antigen using magnetic immuno-chromatography (MICT). J. Virol. Methods 160, 14-21 CrossRef

31 Butler, S.A., Khanlian, S.A. and Cole, L.A. (2001) Detection of early pregnancy forms of human chorionic gonadotropin by home pregnancy test devices. Clin. Chem. 47, 2131-2136 PubMed

32 Mao, X., Ma, Y., Zhang, A., Zhang, L., Zeng, L. and Liu, G. (2009) Disposable nucleic acid biosensors based on gold nanoparticle probes and lateral flow strip. Anal. Chem. 81, 1660-1668 CrossRef PubMed

33 Parolo, C., de la Escosura-Muniz, A. and Merkoci, A. (2013) Enhanced lateral flow immunoassay using gold nanoparticles loaded with enzymes. Biosens. Bioelectron. 40, 412-416 CrossRef PubMed

34 Qiu, W., Xu, H., Takalkar, S., Gurung, A.S., Liu, B., Zheng, Y. et al. (2015) Carbon nanotube-based lateral flow biosensor for sensitive and rapid detection of DNA sequence. Biosens. Bioelectron. 64, 367-372 CrossRef PubMed

35 Ren, M., Xu, H., Huang, X., Kuang, M., Xiong, Y., Xu, H. et al. (2014) Immunochromatographic assay for ultrasensitive detection of aflatoxin B(1) in maize by highly luminescent quantum dot beads. ACS Appl. Mater. Interfaces. 6, 14215-14222 CrossRef PubMed

36 Huang, C., Jones, B.J., Bivragh, M., Jans, K., Lagae, L. and Peumans, P. (2013) A capillary-driven microfluidic device for rapid DNA detection with extremely low sample consumption. 17th International Conference on Miniaturized Systems for Chemistry and Life Sciences, Freiburg, Germany, 27-31 October 2013

37 Anon (2008) Rapid Lateral Flow Test Strips: Considerations for Product Development, Merck Millipore, Billerica

38 Anfossi, L., Di Nardo, F., Giovannoli, C., Passini, C. and Baggiani, C. (2013) Increased sensitivity of lateral flow immunoassay for ochratoxin A through silver enhancement. Anal. Bioanal. Chem. 405, 9859-9867 CrossRef PubMed

39 Lai, W., Tang, D., Que, X., Zhuang, J., Fu, L. and Chen, G. (2012) Enzyme-catalyzed silver deposition on irregular-shaped gold nanoparticles for electrochemical immunoassay of alpha-fetoprotein. Anal. Chim. Acta 755, 62-68 CrossRef PubMed 
40 Tang, D., Sauceda, J.C., Lin, Z., Ott, S., Basova, E., Goryacheva, I. et al. (2009) Magnetic nanogold microspheres-based lateral-flow immunodipstick for rapid detection of aflatoxin B2 in food. Biosens. Bioelectron. 25, 514-518 CrossRef PubMed

41 Qin, Z., Chan, W.C., Boulware, D.R., Akkin, T., Butler, E.K. and Bischof, J.C. (2012) Significantly improved analytical sensitivity of lateral flow immunoassays by using thermal contrast. Angew. Chem. Int. Ed. Engl. 51, 4358-4361 CrossRef

42 Oku, Y., Kamiya, K., Kamiya, H., Shibahara, Y., li, T. and Uesaka, Y. (2001) Development of oligonucleotide lateral-flow immunoassay for multi-parameter detection. J. Immunol. Methods 258, 73-84 CrossRef PubMed

43 Zhu, J., Zou, N., Mao, H., Wang, P., Zhu, D., Ji, H. et al. (2013) Evaluation of a modified lateral flow immunoassay for detection of high-sensitivity cardiac troponin I and myoglobin. Biosens. Bioelectron. 42, 522-525 CrossRef PubMed

44 Chen, J., Fang, Z., Lie, P. and Zeng, L. (2012) Computational lateral flow biosensor for proteins and small molecules: a new class of strip logic gates. Anal. Chem. 84, 6321-6325 CrossRef PubMed

45 Xu, H., Mao, X., Zeng, Q., Wang, S., Kawde, A.N. and Liu, G. (2009) Aptamer-functionalized gold nanoparticles as probes in a dry-reagent strip biosensor for protein analysis. Anal. Chem. 81, 669-675 CrossRef PubMed

46 He, Y., Zhang, X., Zhang, S., Kris, M.K., Man, F.C., Kawde, A.N. et al. (2012) Visual detection of single-base mismatches in DNA using hairpin oligonucleotide with double-target DNA binding sequences and gold nanoparticles. Biosens. Bioelectron. 34, 37-43 CrossRef

47 Liu, C., Jia, Q., Yang, C., Qiao, R., Jing, L., Wang, L. et al. (2011) Lateral flow immunochromatographic assay for sensitive pesticide detection by using Fe304 nanoparticle aggregates as color reagents. Anal. Chem. 83, 6778-6784 CrossRef PubMed

$48 \mathrm{Li}$, Z., Wang, Y., Wang, J., Tang, Z., Pounds, J.G. and Lin, Y. (2010) Rapid and sensitive detection of protein biomarker using a portable fluorescence biosensor based on quantum dots and a lateral flow test strip. Anal. Chem. 82, 7008-7014 CrossRef PubMed

49 Joung, H.A., Oh, Y.K. and Kim, M.G. (2014) An automatic enzyme immunoassay based on a chemiluminescent lateral flow immunosensor. Biosens. Bioelectron. 53, 330-335 CrossRef PubMed

50 Lin, Y.Y., Wang, J., Liu, G., Wu, H., Wai, C.M. and Lin, Y. (2008) A nanoparticle label/immunochromatographic electrochemical biosensor for rapid and sensitive detection of prostate-specific antigen. Biosens. Bioelectron. 23, 1659-1665 CrossRef PubMed

51 Song, L.W., Wang, Y.B., Fang, L.L., Wu, Y., Yang, L., Chen, J.Y. et al. (2015) Rapid fluorescent lateral-flow immunoassay for hepatitis B virus genotyping Anal. Chem. 87, 5173-5180 CrossRef PubMed

52 Venkatraman, V. and Steckl, A.J. (2015) Integrated OLED as excitation light source in fluorescent lateral flow immunoassays. Biosens. Bioelectron. 74, 150-155 CrossRef PubMed

53 Wang, D.B., Tian, B., Zhang, Z.P., Wang, X.Y., Fleming, J., Bi, L.J. et al. (2015) Detection of Bacillus anthracis spores by super-paramagnetic lateral-flow immunoassays based on "Road Closure". Biosens. Bioelectron. 67, 608-614 CrossRef PubMed

54 Mirasoli, M., Buragina, A., Dolci, L.S., Guardigli, M., Simoni, P., Montoya, A. et al. (2012) Development of a chemiluminescence-based quantitative lateral flow immunoassay for on-field detection of 2,4,6-trinitrotoluene. Anal. Chim. Acta 721, 167-172 CrossRef PubMed

55 Maiolini, E., Ferri, E., Pitasi, A.L., Montoya, A., Di Giovanni, M., Errani, E. et al. (2014) Bisphenol A determination in baby bottles by chemiluminescence enzyme-linked immunosorbent assay, lateral flow immunoassay and liquid chromatography tandem mass spectrometry. Analyst 139 318-324 CrossRef PubMed 